\title{
Does infant feeding method impact maternal mental health?
}

Running title: Breastfeeding and mental health

Fenglian $\mathrm{Xu}^{1} \mathrm{BMed}, \mathrm{MPH}, \mathrm{PhD}$, Zhuoyang Li ${ }^{1} \mathrm{BMed} \mathrm{MPH}$, Colin Binns ${ }^{2} \mathrm{MBBS}, \mathrm{MPH}, \mathrm{PhD}$, Michelle

Bonello ${ }^{1} B S c$ (Hon), MPH, PhD , Marie-Paule Austin ${ }^{3} \mathrm{MBBS}, \mathrm{MD}$, Elizabeth Sullivan ${ }^{1} \mathrm{MBBS}, \mathrm{MPH}, \mathrm{MD}$

${ }^{1}$ National Perinatal Epidemiology and Statistics Unit, University of New South Wales, Sydney, Australia

${ }^{2}$ School of public health and Curtin Health Innovation Research Institute, Curtin University, Perth, Australia

${ }^{3}$ St John of God Health Care \& School of Psychiatry, University of New South Wales, Sydney, Australia

Correspondence Author:

Dr Fenglian Xu

National Drug and Alcohol Research Centre

The University of New South Wales

32 King ST, Randwick, NSW 2031, Australia

Tel: +61(2) 89361013 Fax: +61(2) 93850222 Email: f.xu@unsw.edu.au 


\begin{abstract}
Background: Breastfeeding has been reported to reduce the risk of postpartum anxiety and depression. However, little is known of effects of breastfeeding on hospital admissions for postpartum mental disorders.
\end{abstract}

Method: This is a population-based longitudinal cohort study using linked data. All mothers who gave birth to a live infant between 2007 and 2008 in NSW were followed up for one year for hospital admissions with diagnoses of psychiatric and/or substance use disorders.

Results: There were 186,452 women who were reported as giving birth in NSW between 2007 and 2008. The 'any breastfeeding' rate at the time of discharge was $87.1 \%$. A total of 2,940 mothers were admitted to hospital with psychiatric diagnoses within 12 months of birth. The first hospital admission for the diagnoses of overall mental illness was 32 days earlier for non-breastfeeding mothers compared with those with full breastfeeding. Mothers who did not breastfeed were more likely to be admitted to hospital in the first year postpartum for schizophrenia (adjusted relative risk $(A R R)=2.0,95 \%$ confidence interval $(C I): 1.3-3.1)$; bipolar affective disorders (ARR=1.9, 95\% Cl: 1.13.5), and mental illness due to substance use ( $A R R=1.8,95 \% \mathrm{Cl}: 1.3-2.5)$ compared with full breastfeeding mothers.

Conclusion: Breastfeeding is associated with a decrease in the risk of subsequent maternal hospital admissions for schizophrenia, bipolar affective disorders and mental illness due to substance use, in the first postpartum year.

Key words: Breastfeeding, Psychiatric Disorder, Substance Use, Postpartum, Data Linkage 


\section{Introduction}

Postpartum mental health problems are recognized as a major public health concern and are associated with poor outcomes for women and their children and families ${ }^{1,2}$. It is reported that one in five women experience a mental health disorder during the postpartum period, with problems including depression, anxiety disorders, post-traumatic stress disorder, obsessive-compulsive disorder to bipolar disorder, schizophrenia and psychosis ${ }^{3-9}$. Mental health problems arising in the perinatal period may become chronic and carry over to future pregnancies ${ }^{10-12}$. Maternal mental illness can also have adverse effects on the cognitive, social, and emotional development of infants due to impaired maternal-infant interactions ${ }^{13-15}$.

Breastfeeding results in improved health outcomes for both infants and mothers ${ }^{16-18}$. Previous studies have shown an association between post-partum depression and breastfeeding. A systematic review of breastfeeding and maternal health outcomes in developed countries shown that short duration of breastfeeding or not breastfeeding was associated with elevated risk of postpartum depression ${ }^{17}$. Watkins and colleagues found that women with negative early breastfeeding experiences, including breastfeeding pain in the first day, were more likely to experience postpartum depression at 2 months ${ }^{19}$. A quasi-experimental study in Pakistan found that difficulty in breastfeeding at birth was significantly associated with postpartum anxiety and depression ${ }^{20}$. However, little is known of effects of breastfeeding on other postpartum mental disorders. In addition, the majority of studies provided information related to postpartum depression and breastfeeding used Edinburgh Postnatal Depression Scale or other self-report measures of postpartum depression ${ }^{21}$, where mothers with postpartum depressive symptoms do not necessarily have clinical diagnosis of depression. Of the few studies using clinical diagnoses of mental disorders occurring within the first postpartum year, none have reported an association between infant feeding method and the interval between birth and hospital admission The objective of this study is to explore the relationship between early breastfeeding experience and clinical- 
diagnosed postpartum mental disorders and to examine associations between early breastfeeding experience and the interval between birth and the first-time hospital admission for mental disorders. 


\section{Materials and methods}

\section{Study population and design}

The study population included all mothers who gave birth to a live infant between 2007 and 2008 in New South Wales (NSW), Australia. This is a population-based longitudinal cohort study using linked data from the NSW Midwives Data Collection (MDC) and the NSW Admitted Patients Data Collection (APDC). The MDC covered all births in public and private hospitals as well as home births in NSW. The data recorded in the MDC included infant feeding practices, demographic and obstetric information. The hospital admissions data (APDC) is a routinely collected census of all hospital separations and includes all patient hospitalisations in NSW public and private hospitals, including psychiatric hospitals and day procedures. Since 1999, diagnoses for admissions have been coded according to the 10th revision of the International Statistical Classification of Diseases and Related Health Problems, Australian Modification (ICD-10-AM) ${ }^{22}$. Since 2007, infant feeding practices at discharge from hospital or care for home births has been reported for all infants born in NSW. The NSW Midwives Data Collection form includes the question: 'Infant feeding on hospital discharge (tick one or more)' and the answer options are 'breastfeeding', 'expressed breastmilk, and 'infant formula'. Using linked databases details of all hospital admissions with the diagnoses of psychiatric and substance use disorders within one year of delivery were analysed.

Diagnosis of mental and behavioral disorders

The diagnoses for each admission in this study were coded according to ICD-10-AM ${ }^{22}$. Mothers with mental disorders were identified using the ICD-10-AM diagnosis codes: (1) schizophrenia, schizophrenia-like disorders including delusional and schizoaffective disorders (F20-22, F24-29); (2) Unipolar depressions (F32 (excluding 32.3), F33 (excluding 33.3 and 33.4), F34, F38, F39, F53.0); (3) Acute psychoses: reactive, brief, affective (F23, 30.2, 31.2, 31.5, 32.3, 33.3, 53.1). (4) Bipolar affective disorders (bipolar affective disorders F30 (excluding F30.2), F31 (exclude F31.2), F31.5, 
F31.7); (5) Anxiety disorders (F40, 41, 42); (6) adjustment disorders (F43). (6) Anxiety disorders (F4042); (7) personality disorders (F60-69); (8) Mental illness due to substance use F10-19.The "overall" group consisted of these 8 categories plus the remaining F00-99 psychiatric diagnoses. In this study, only principal diagnoses which were chiefly responsible for the hospital admission ${ }^{23}$ were used for the analysis.

Data linkage

The Data linkage between the MDC and APDC was performed by the NSW Department of Health Centre for Health Record Linkage (CHeReL) using probabilistic record linkage methods and ChoiceMaker software (www.cherel.org.au). Identifying information from MDC and APDC datasets was included in the Master Linkage Key constructed by the CHeReL. Each record was assigned a number, Person Project Number, to allow records for the same mother to be linked. Based on the 1,000 randomly selected samples of the records, the false positive rate of the linkage was $0.5 \%$. Statistical analysis

Cox regression models were used to analyse the relative risk (RR) and $95 \%$ confidence intervals. The Kaplan-Meier method was used to describe mean and median of the non-admission days and $95 \%$ confidence interval (CI) for MBD. The analyses were conducted using IBM SPSS Statistics 20 (http://www-01.ibm.com/software/analytics/spss/).

\section{Ethics approval}

This study was approved by the NSW Population \& Health Services Research Ethics Committee and the Human Research Ethics Committee of the University of New South Wales, Australia. 


\section{Results}

There were 186,452 women who were reported to give birth in NSW, Australia between 1 January 2007 and 31 December 2008 (Table 1). Of these women, 150,343 (80.6\%) were reported to be full breastfeeding and 24,032 (6.5\%) were reported to be breastfeeding with formula at the time of discharge from hospital or discharge from care for home births. The 'any breastfeeding' rate which included either 'full breastfeeding' or breastfeeding combined with formula was $87.1 \%$ while nonbreastfeeding (infant formula only) rate was $12.9 \%$ (Table 1 ).

Compared with 'full breastfeeding' mothers, mothers who did not breastfeed at the time of discharge from hospital or care for home births were more likely to be admitted to hospital in the first year postpartum for schizophrenia (adjusted relative risk $(A R R)=2.0,95 \%$ confidence interval (CI): 1.3-3.1), bipolar affective disorders ( $A R R=1.9,95 \% \mathrm{Cl}: 1.1-3.5)$, and mental illness due to substance use (ARR=1.8, 95\% Cl: 1.3-2.5). However, non-breastfeeding mothers were less likely to be admitted to hospital with a diagnosis of anxiety disorders (ARR=0.6, 95\% Cl: $0.5-0.9$ ) within 12 months after births (Table 1).

A total of 2,940 (1.6\%) mothers were admitted to hospital for mental and behavioural disorders within 12 months after birth, 1,037 (0.6\%) were diagnosed with adjustment disorders, 971 (0.5\%) were diagnosed with unipolar depression, and $585(0.3 \%)$ were diagnosed with anxiety disorders (Table 2). The mean time period before first hospital admission with a diagnosis of any mental illness was 169 days for 'full breastfeeding' mothers, which was 32 days longer than the 137 days for nonbreastfeeding mothers $(P<0.05)$. The first hospital admission for diagnoses of anxiety disorder, unipolar depressions, and adjustment disorders occurred earlier (on average 41, 36, and 31 days, respectively) $(P<0.05)$ in non-breastfeeding mothers compared with full breastfeeding mothers (Table 2). 


\section{Discussion}

The 'any breastfeeding' rate of $87.1 \%$ found in this cohort is consistent with that reported in a previous newborn feeding practices study in NSW ${ }^{18}$. Breastfeeding rates at the time of discharge are in keeping with the Australian national target of at least $90 \%$ of babies being initially breastfed ${ }^{24}$. Psychiatric disorders in the postpartum period are an important public health issue. This study found that approximately one in sixty women who gave birth in NSW between 2007 and 2008 were admitted to hospital for mental and behaviour disorder at least once within 12 months after birth. This represents a large burden on the hospital system and is a cause of considerable disruption on the families of these mothers. Better maternal mental health outcomes were reported for full breastfeeding mothers compared with non-breastfeeding mothers at the time of discharge from hospital or discharge from care for home births. Breastfeeding at this time was associated with a decrease in the risk of hospital admission due to mental and behaviour disorders, including schizophrenia, bipolar affective disorders and mental illness due to substance use within first postpartum year. In addition, fully breastfeeding at the time of discharge delayed the first postpartum admission for unipolar depressions, adjustment disorders and anxiety disorders. Although the benefits of breastfeeding are well documented, as are the negative health consequences of postpartum mental disorders, it is unclear whether breastfeeding status influences postpartum mental disorders or vice versa. Henderson and colleagues found that postpartum depressive symptomatology was associated with early cessation of breastfeeding ${ }^{25}$. A populationbased study for 594 Canadian mothers reported that those with high Edinburgh Postnatal Depression Scale scores at 1 week postpartum were more likely to discontinue breastfeeding at 4 and/or 8 weeks ${ }^{26}$. However, the use of breastfeeding status at the time of discharge in our study minimizes the negative influence of maternal mood on infant feeding outcome. As the median postnatal length of stay for mothers was 3 days in Australia ${ }^{27}$, the breastfeeding status at the time of discharge reflects the early breastfeeding experience in hospital, rather than the influence of 
depressive symptomatology. Therefore, the decreased risk of postpartum mental and behavioural disorder admission for full breastfeeding mothers at the time of discharge suggests a protective effect of breastfeeding on postpartum maternal mental health. The findings in our study indicated the directional effect of early breastfeeding experience on maternal mental health outcomes.

This was the first population-based study to evaluate the influence of early breastfeeding experience on the non-admission days of postpartum admission for mental and behavioural disorders. On average, the first postpartum admission for mental and behaviour disorders for full breastfeeding mothers occurred one month later than non-breastfeeding mothers. Mothers are vulnerable to a wide spectrum of mental disorders during the postpartum period which involves the transition to new motherhood and changes in relationships within families. Breastfeeding is a facilitator of mother-infant bonding, which increases maternal satisfaction, decreases negative mood and reduces perceived stress in mothers ${ }^{28,29}$. These psychological benefits of breastfeeding may help to defer the onset of mental and behaviour disorders. Conversely, the delay in psychiatric admission for mothers who are breastfeeding, may be associated with a reluctance by the mother to wean, (as psychiatric mother-infant admissions are not available to the majority of these families) hence delaying admission for infant feeding reasons.

Limitations of this study include the lack of evaluation of infant-feeding methods at regular intervals during the postpartum period. The dataset used for this study was an administrative perinatal data with limited information on infant feeding method after women were discharged from hospital or from care for home births. A future cohort study should be conducted to examine the presence of a psychiatric illness during the antenatal period or at the time of delivery as this could influence the choice of the infant feeding method. Additional information is needed on breastfeeding status at the time of psychiatric admission to suggest the directional effect of breastfeeding and clinical admission for mental and behaviour disorders. Mothers who chose not to initiate breastfeeding 
should be distinguished with mothers who prematurely discontinued breastfeeding due to low selfefficacy, experiencing breastfeeding difficulties, or having a physiologically insufficient milk supply.

\section{Conclusions}

Breastfeeding is associated with a decrease in the risk of maternal hospital admissions for schizophrenia, bipolar affective disorders and mental illness due to substance use across the first postpartum year. The decreased risk and delayed admission of postpartum mental and behavioural disorder for full breastfeeding mothers at the time of discharge suggest a protective effect of breastfeeding on postpartum maternal mental health and an effect of early breastfeeding experience on maternal mental health outcomes. If confirmed these findings have the potential to improve the health of mothers and to reduce health service costs. These findings will need replication with methodologies addressing breastfeeding status at the time of psychiatric admission. 


\section{Acknowledgements}

We would like to thank data custodians Jason Bentley, Zoran Bolevich, Lee Taylor, Kim Lim and Sarah Thackway of NSW Ministry of Health; Elizabeth Moore and Katie Irvine of the Centre for Health Record Linkage (CheReL) for providing the data, undertaking the linkage and providing expert technical advices. We acknowledge Australian National Health and Medical Research Council (NHMRC) Training Fellowship for providing the funding for this study. We acknowledge the families who have contributed their data to this study. 


\section{Reference}

1. Buist A, Bilszta J, Barnett B, et al. Recognition and management of perinatal depression in general practice--a survey of GPs and postnatal women. Aust Fam Physician. Sep 2005;34(9):787-790.

2. Yelland JS, Sutherland GA, Wiebe JL, Brown SJ. A national approach to perinatal mental health in Australia: exercising caution in the roll-out of a public health initiative. Med J Aust. Sep 7 2009;191(5):276-279.

3. Austin MP, Priest SR, Sullivan EA. Antenatal psychosocial assessment for reducing perinatal mental health morbidity. Cochrane Database Syst Rev. 2008(4):CD005124.

4. Blackmore ER. Postpartum mood and anxiety disorders: A clinician's guide. Birth-Issues in Perinatal Care. Jun 2008;35(2):165-166.

5. Sharma V. Treatment of postpartum psychosis: challenges and opportunities. Current Drug Safety. Jan 2008;3(1):76-81.

6. Speisman BB, Storch EA, Abramowitz JS. Postpartum obsessive-compulsive disorder. JOGNN - Journal of Obstetric, Gynecologic, \& Neonatal Nursing. Nov-Dec 2011;40(6):680-690.

7. Sharma V, Burt VK, Ritchie HL. Bipolar II postpartum depression: Detection, diagnosis, and treatment. American Journal of Psychiatry. Nov 2009;166(11):1217-1221.

8. Fisher J, Cabral de Mello M, Patel V, et al. Prevalence and determinants of common perinatal mental disorders in women in low- and lower-middle-income countries: a systematic review. Bull World Health Organ. Feb 1 2012;90(2):139G-149G.

9. Brockington I. Postpartum psychiatric disorders. Lancet. Jan 24 2004;363(9405):303-310.

10. Austin MP, Lumley J. Antenatal screening for postnatal depression: a systematic review. Acta Psychiatr Scand. Jan 2003;107(1):10-17. 
11. Nager A, Szulkin R, Johansson SE, Johansson LM, Sundquist K. High lifelong relapse rate of psychiatric disorders among women with postpartum psychosis. Nord J Psychiatry. Feb 2013;67(1):53-58.

12. Cooper PJ, Murray L. Course and recurrence of postnatal depression. Evidence for the specificity of the diagnostic concept. Br J Psychiatry. Feb 1995;166(2):191-195.

13. Murray L, Cooper P. Effects of postnatal depression on infant development. Arch Dis Child. Aug 1997;77(2):99-101.

14. Murray L, Arteche A, Fearon P, Halligan S, Goodyer I, Cooper P. Maternal postnatal depression and the development of depression in offspring up to 16 years of age. J Am Acad Child Adolesc Psychiatry. May 2011;50(5):460-470.

15. Murray L, Arteche A, Fearon P, Halligan S, Croudace T, Cooper P. The effects of maternal postnatal depression and child sex on academic performance at age 16 years: a developmental approach. J Child Psychol Psychiatry. Oct 2010;51(10):1150-1159.

16. Dieterich CM, Felice JP, O'Sullivan E, Rasmussen KM. Breastfeeding and health outcomes for the mother-infant dyad. Pediatric Clinics of North America. Feb 2013;60(1):31-48.

17. Ip S, Chung M, Raman G, et al. Breastfeeding and maternal and infant health outcomes in developed countries. Evidence Report/Technology Assessment. Apr 2007(153):1-186.

18. National Health and Medical Research Council. Infant Feeding Guidelines. Canberra: National Health and Medical Research Council; 2012.

19. Watkins S, Meltzer-Brody S, Zolnoun D, Stuebe A. Early breastfeeding experiences and postpartum depression. Obstetrics \& Gynecology. Aug 2011;118(2 Pt 1):214-221.

20. Ali NS, Ali BS, Azam IS. Post partum anxiety and depression in peri-urban communities of Karachi, Pakistan: a quasi-experimental study. BMC Public Health. 2009;9:384.

21. Dennis $\mathrm{CL}$, McQueen K. The relationship between infant-feeding outcomes and postpartum depression: a qualitative systematic review. Pediatrics. Apr 2009;123(4):e736-751. 
22. National Centre for Classification in Health. The international statistical classification of diseases and related health problems, 10th revision, Australian modification (ICD-10-AM). Sydney: National Centre for Classification in Health; 1999.

23. Australian Institute of Health and Welfare. Australian hospital statistics 2008-09. Health services series no. 17. Cat. no. HSE 84. . Canberra: AlHW; 2010.

24. National Health and Medical Research Council. Dietary guidelines for children and adolescents in Australia, incorporating infant feeding guidelines for health workers. Canberra: National Health and Medical Research Council; 2003.

25. Henderson JJ, Evans SF, Straton JA, Priest SR, Hagan R. Impact of postnatal depression on breastfeeding duration. Birth. Sep 2003;30(3):175-180.

26. Dennis $\mathrm{CL}$, McQueen K. Does maternal postpartum depressive symptomatology influence infant feeding outcomes? Acta Paediatr. Apr 2007;96(4):590-594.

27. Li Z, Zeki R, Hilder L, Sullivan EA. Australia's mothers and babies 2010. Canberra: Canberra: Australian Institute of Health and Welfare, 2012.; 13 December 2012 2012. AlHW Catalogue no PER 57.

28. Leung AK, Sauve RS. Breast is best for babies. J Natl Med Assoc. Jul 2005;97(7):1010-1019.

29. Mezzacappa ES, Katlin ES. Breast-feeding is associated with reduced perceived stress and negative mood in mothers. Health Psychol. Mar 2002;21(2):187-193.

\section{Address and e-mail address for reprint requests or correspondence}

National Drug and Alcohol Research Centre (NDARC)

Address: 32 King ST, Randwick NSW 2031 Australia

f.xu@unsw.edu.au 
Table 1 The risk of first-time hospital admission for mental illness in the first year postpartum in different infant feeding groups, in New South Wales, Australia, 2007-2008

\begin{tabular}{|c|c|c|c|c|}
\hline Diagnosis & Feeding method & $\mathrm{N}$ & Crude RR (95\% Cl) & Adjusted RR $(95 \% \mathrm{Cl})^{\wedge}$ \\
\hline \multirow{3}{*}{ Schizophrenia } & Non breastfeeding & 24032 & $3.7(2.5,5.6)$ & $2.0(1.3,3.1)$ \\
\hline & Breastfeeding with formula & 12077 & $2.0(1.1,4.0)$ & $1.7(0.9,3.4)$ \\
\hline & Breastfeeding & 150343 & 1.0 & 1.0 \\
\hline \multirow{3}{*}{$\begin{array}{c}\text { Unipolar } \\
\text { depressions }\end{array}$} & Non breastfeeding & 24032 & $1.0(0.8,1.2)$ & $1.0(0.8,1.2)$ \\
\hline & Breastfeeding with formula & 12077 & $1.0(0.8,1.3)$ & $1.0(0.8,1.3)$ \\
\hline & Breastfeeding & 150343 & 1.0 & 1.0 \\
\hline \multirow{3}{*}{$\begin{array}{c}\text { Acute } \\
\text { psychotic } \\
\text { episodes }\end{array}$} & Non breastfeeding & 24032 & $1.5(1.0,2.3)$ & $1.3(0.8,2.1)$ \\
\hline & Breastfeeding with formula & 12077 & $1.1(0.6,2.1)$ & $1.1(0.5,2.2)$ \\
\hline & Breastfeeding & 150343 & 1.0 & 1.0 \\
\hline \multirow{3}{*}{$\begin{array}{l}\text { Bipolar } \\
\text { affective } \\
\text { disorders }\end{array}$} & Non breastfeeding & 24032 & $2.5(1.4,4.3)$ & $1.9(1.1,3.5)$ \\
\hline & Breastfeeding with formula & 12077 & $2.0(0.9,4.5)$ & $2.2(1.0,5)$ \\
\hline & Breastfeeding & 150343 & 1.0 & 1.0 \\
\hline \multirow{3}{*}{$\begin{array}{l}\text { Adjustment } \\
\text { disorders }\end{array}$} & Non breastfeeding & 24032 & $0.8(0.7,1.0)$ & $0.9(0.7,1.1)$ \\
\hline & Breastfeeding with formula & 12077 & $1.1(0.9,1.4)$ & $1.0(0.8,1.3)$ \\
\hline & Breastfeeding & 150343 & 1.0 & 1.0 \\
\hline \multirow{3}{*}{$\begin{array}{l}\text { Anxiety } \\
\text { disorders }\end{array}$} & Non breastfeeding & 24032 & $0.5(0.4,0.7)$ & $0.6(0.5,0.9)$ \\
\hline & Breastfeeding with formula & 12077 & $1(0.7,1.3)$ & $0.9(0.7,1.3)$ \\
\hline & Breastfeeding & 150343 & 1.0 & 1.0 \\
\hline \multirow{3}{*}{$\begin{array}{l}\text { Personality } \\
\text { disorders }\end{array}$} & Non breastfeeding & 24032 & $3.9(2.2,6.9)$ & $1.7(0.9,3.0)$ \\
\hline & Breastfeeding with formula & 12077 & $0.4(0.1,2.9)$ & $0.4(0.1,2.9)$ \\
\hline & Breastfeeding & 150343 & 1.0 & 1.0 \\
\hline \multirow{3}{*}{$\begin{array}{l}\text { Mental illness } \\
\text { due to } \\
\text { substance use }\end{array}$} & Non breastfeeding & 24032 & $4.0(2.9,5.5)$ & $1.8(1.3,2.5)$ \\
\hline & Breastfeeding with formula & 12077 & $1.4(0.8,2.6)$ & $1.4(0.8,2.7)$ \\
\hline & Breastfeeding & 150343 & 1.0 & 1.0 \\
\hline \multirow{3}{*}{$\begin{array}{c}\text { Overall } \\
\text { mental illness }\end{array}$} & Non breastfeeding & 24032 & $1.0(0.9,1.1)$ & $1.0(0.9,1.2)$ \\
\hline & Breastfeeding with formula & 12077 & $1.1(0.9,1.3)$ & $1.0(0.9,1.2)$ \\
\hline & Breastfeeding & 150343 & 1.0 & 1.0 \\
\hline
\end{tabular}


Table 2 Infant feeding practice and the non-admission days after birth for the first-time hospital admission for mental illness in New South Wales, Australia, 2007-2008

\begin{tabular}{|c|c|c|c|c|}
\hline Diagnosis & Feeding method & $\mathrm{N}(\%)$ & Mean $(95 \% \mathrm{Cl})$ (days) & Median(95\% Cl) (days) \\
\hline \multirow{4}{*}{ Schizophrenia } & Non breastfeeding & $36(0.1)$ & $118(84,151)$ & $87(19,155)$ \\
\hline & Breastfeeding with formula & $10(0.1)$ & $136(81,190)$ & $123(18,228)$ \\
\hline & Breastfeeding & $61(0.0)$ & $139(114,164)$ & $111(92,130)$ \\
\hline & Overall & $107(0.1)$ & $131(112,150)$ & $110(83,137)$ \\
\hline \multirow{4}{*}{$\begin{array}{c}\text { Unipolar } \\
\text { depressions }\end{array}$} & Non breastfeeding & $124(0.5)$ & $120(104,135)$ & $91(73,109)$ \\
\hline & Breastfeeding with formula & $63(0.5)$ & $149(127,171)$ & $136(108,164)$ \\
\hline & Breastfeeding & $784(0.5)$ & $156(149,163)$ & $139(126,152)$ \\
\hline & Overall & $971(0.5)$ & $151(145,157)$ & $136(125,147)$ \\
\hline \multirow{4}{*}{$\begin{array}{c}\text { Acute } \\
\text { psychotic } \\
\text { episodes }\end{array}$} & Non breastfeeding & $25(0.1)$ & $122(81,164)$ & $90(64,116)$ \\
\hline & Breastfeeding with formula & $9(0.1)$ & $98(37,159)$ & $77(39,115)$ \\
\hline & Breastfeeding & $104(0.1)$ & $94(77,111)$ & $64(47,81)$ \\
\hline & Overall & $138(0.1)$ & $99(84,115)$ & $71(54,88)$ \\
\hline \multirow{4}{*}{$\begin{array}{l}\text { Bipolar } \\
\text { affective } \\
\text { disorders }\end{array}$} & Non breastfeeding & $17(0.1)$ & $132(71,193)$ & $62(0,157)$ \\
\hline & Breastfeeding with formula & $7(0.1)$ & $155(78,233)$ & $196(0,501)$ \\
\hline & Breastfeeding & $43(0.0)$ & $146(116,175)$ & $141(110,172)$ \\
\hline & Overall & $67(0.0)$ & $143(118,168)$ & $136(96,176)$ \\
\hline \multirow{4}{*}{$\begin{array}{l}\text { Adjustment } \\
\text { disorders }\end{array}$} & Non breastfeeding & $108(0.4)$ & $138(120,156)$ & $108(77,139)$ \\
\hline & Breastfeeding with formula & $75(0.6)$ & $136(116,157)$ & $97(80,114)$ \\
\hline & Breastfeeding & $854(0.6)$ & $169(162,175)$ & $156(142,170)$ \\
\hline & Overall & $1037(0.6)$ & $163(157,169)$ & $146(135,157)$ \\
\hline \multirow{4}{*}{$\begin{array}{l}\text { Anxiety } \\
\text { disorders }\end{array}$} & Non breastfeeding & $39(0.2)$ & $144(113,174)$ & $128(108,148)$ \\
\hline & Breastfeeding with formula & $39(0.3)$ & $170(139,202)$ & $150(50,250)$ \\
\hline & Breastfeeding & $507(0.3)$ & $185(177,193)$ & $190(176,204)$ \\
\hline & Overall & $585(0.3)$ & $182(174,189)$ & $186(171,201)$ \\
\hline \multirow{4}{*}{$\begin{array}{l}\text { Personality } \\
\text { disorders }\end{array}$} & Non breastfeeding & $20(0.1)$ & $120(83,158)$ & 109(19,199) \\
\hline & Breastfeeding with formula & $1(0.0)$ & $152(152,152)$ & $152(152,152)$ \\
\hline & Breastfeeding & $32(0.0)$ & $161(128,195)$ & $134(69,199)$ \\
\hline & Overall & $53(0.0)$ & $146(121,171)$ & $137(107,167)$ \\
\hline \multirow{4}{*}{$\begin{array}{c}\text { Mental illness } \\
\text { due to } \\
\text { substance }\end{array}$} & Non breastfeeding & $63(0.3)$ & $182(159,204)$ & $184(155,213)$ \\
\hline & Breastfeeding with formula & $11(0.1)$ & $147(102,192)$ & $143(104,182)$ \\
\hline & Breastfeeding & $98(0.1)$ & $205(186,224)$ & $210(188,232)$ \\
\hline & Overall & $172(0.1)$ & $193(178,207)$ & $200(181,219)$ \\
\hline \multirow{4}{*}{$\begin{array}{c}\text { Overall } \\
\text { mental illness }\end{array}$} & Non breastfeeding & $384(1.6)$ & $137(128,147)$ & $126(109,143)$ \\
\hline & Breastfeeding with formula & $204(1.7)$ & $148(135,160)$ & $125(104,146)$ \\
\hline & Breastfeeding & $2352(1.6)$ & $169(165,172)$ & $160(152,168)$ \\
\hline & Overall & $2940(1.6)$ & $163(159,167)$ & $152(145,159)$ \\
\hline
\end{tabular}

